\title{
Tobacco use among population sub-groups: A gender analysis
}

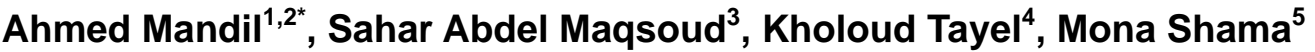 \\ ${ }^{1}$ Epidemiology Department, High Institute of Public Health [HIPH], Alexandria University, Alexandria, Egypt \\ ${ }^{2}$ College of Medicine, King Saud University, Riyadh, KSA; *Corresponding Author: ahmed.mandil@yahoo.com \\ ${ }^{3}$ Preventive Affairs Department, Alexandria University Students' Clinic and Hospital, Alexandria, Egypt \\ ${ }^{4}$ Family Health Department, High Institute of Public Health, University of Alexandria, Alexandria, Egypt \\ ${ }^{5}$ Health Education Department, High Institute of Public Health, University of Alexandria, Alexandria, Egypt
}

Received 7 August 2012; revised 11 September 2012; accepted 24 October 2012

\section{ABSTRACT}

Women comprise $20 \%$ of world's billion smokers. Especially troubling is raising prevalence of tobacco use among girls. In fact, it is expected that $20 \%$ of women in developing/developed countries will be smokers by 2025 . This study analytically compares knowledge, attitudes, and practices of tobacco use, by gender, among 4 sub-populations in Alexandria, Egypt. Methods: A cross sectional approach was used for 4 subgroups (high school students, university students, shopping malls/clubs' attendees, employees of health-related facilities), 1000 each (total sample size $=4000$ ). A modified version of WHO questionnaire was used for data collection. Results: Smoking prevalence was generally higher among males (29\% - $44 \%)$ compared to females $(2 \%-9 \%)$ in the studied groups. Cafeterias were preferable smoking places for both genders, especially among high school/university students. Most smokers in the 4 subgroups reported that most or all their friends were smokers. Mean knowledge scores were found to be higher among male employees/high school students, compared to females in the same subgroups. Mean attitude scores towards smoking were higher among females (i.e. against smoking) in the 4 sub-samples. Conclusion \& Recommendations: Tobacco use among males is generally higher among males, but females seem to be catching up. Social gatherings seem to attract many youngsters, of both genders, to smoke in public, especially water-pipe (which is a growing epidemic of tobacco use in our communities). Mass community- and gender-based health awareness campaigns are needed, using different channels, including school-based health education interventions, at the earliest age pos- sible.

Keywords: Tobacco Use; Gender Analysis; Population Sub-Groups

\section{INTRODUCTION}

Worldwide, tobacco kills more men than women as historically smoking prevalence has been higher among men in many countries. However, because smoking rates are increasing among women in different countries, particularly among young females, the gap in tobacco death rates between men and women is closing [1]. The Eastern Mediterranean Region (EMR) faces a great challenge regarding tobacco epidemic due to the high rates of tobacco consumption. About half of the region's adult men and about $10 \%$ of adult women are current smokers, and the situation among youth of both sexes is even more serious. WHO report (2009) on the global tobacco epidemic documented that the prevalence of current tobacco use among adult men ranged from $24 \%$ $61 \%$, as compared to $2 \%-31 \%$ among women in EMR nations [2].

A national household study carried out by the Global Adult Tobacco Survey (GATS) in Egypt in the year 2009 reported that $19.7 \%$ of the Egyptian population aged 15 years and older used some form of tobacco product [3]. The prevalence of current tobacco smoking was $59.3 \%$ among adult males and $2.7 \%$ among adult females [2]. A cross sectional survey on tobacco use in Alexandria, Egypt (2002) revealed that the prevalence of current smokers was $27.2 \%$ with prevalence of smoking among men was $48.5 \%$, as compared to only $1.5 \%$ among women [4].

Water-pipe smoking is now spreading to many countries in the EMR; particularly among young men and women [5]. The authors anticipated major differences between males and females, among different age and 
population groups in Alexandria, Egypt, when it comes to awareness about, perceptions towards and consumption of tobacco products. We also needed to objectively confirm the observed popularity of water-pipe smoking among women, as compared to men. Thus, this study aimed at analytically comparing knowledge, attitudes, and practices of tobacco use, by gender, among 4 subpopulations in Alexandria

\section{MATERIAL \& METHODS}

A cross sectional design was used to detect magnitude and study consumption pattern (type and frequency), knowledge, attitude and behavioral factors of tobaccouse in Alexandria The study was conducted in selected settings in Alexandria involving different population subgroups (i.e. governmental high schools; university colleges; hospitals and clinics of University of Alexandria; two sporting and social clubs and two main shopping malls in Alexandria).

Sample size was estimated to be $(\approx 4000)$, using $95 \%$ confidence level and $2 \%$ degree of precision [6]. The required sample size was equally divided between the 4 previously mentioned population subgroups i.e. 1000 for each sub group, with equal distribution between males and females. Details for each of the 4 sub-groups' sample selection are provided below.

A multi-stage stratified random sampling technique was utilized for high school students' selection, from the 7 educational zones of Alexandria. Two general high school schools (one for boys, one for girls) were randomly selected from each zone, by blind paper picking method. Two classes were randomly chosen from each school (one from grade one and one from grade 3 ) as to fulfill the required sample size of 144 students within a period of 2 months (thus 72 males and 72 females from each school in each educational zone were chosen randomly).

Regarding the university (undergraduate students) sample, two humanities colleges were chosen (arts and commerce) by blind paper picking method from the main campus of colleges for humanities' studies in Alexandria; two health related faculties (medicine and dentistry) were randomly chosen (same method) from the main campus of colleges for health studies in Alexandria, during 2008. An equal number of male and female students were included from each selected college.

Five hundred attendees from two Alexandria sporting clubs were selected for this study. Similarly, 500 visitors to two shopping malls were included in this study. An equal number of male and female participants (i.e. 250 from each club and 250 from each mall) were selected.

All health professionals, including physicians and nurses, as well all non health related employees who were working at Alexandria University Students' Hospital and clinics to fulfill the required sample size over a period of one month (500 health professionals and 500 non health related employees with equal distribution of males and females in both groups).

A modified version of the WHO-GYTS [7] and ESPRI [8] questionnaires were used for data collection, using self administrated method. The questionnaire was divided into four sections: demographic data; knowledge about tobacco use; attitude towards tobacco use as well as laws and rules governing its sales and advertising and behaveioral patterns, including risk factors and cessation attempts. Thus, the tool included questions on: 1) demographic data: age; gender; marital status; occupation, education, income; 2) knowledge about tobacco use: knowledge about smoking hazards and complications; knowledge about methods for smoking cessation, etc.; 3) attitude towards tobacco use and regulations: attitude towards friends smoking; parents smoking (as appropriate, for school-age children); attitude towards smokers; reasons that make people start smoking; attitude towards smoking advertisements; attitude towards cigarette sale age restriction; attitude towards (cigarette and water-pipe) smoking in front of parents (for school-age children); 4) behavioral patterns with respect to tobacco use: smoking frequency; age of initiation of smoking; intention for cessation of smoking.

Definitions [9]:

- Current Smoker: someone who, at the time of the survey, smokes any tobacco product either daily or occasionally.

- Never Smoker: someone who has never smoked at all.

- Non Smoker: someone who was not a smoker at the time of the survey, whether because of being a never smoker or ex daily or ex occasional smoker.

SPSS and Microsoft Office Excel 2003 were used for data analysis. Descriptive statistics were used, as appropriate, in addition to chi-squared test for testing associations between categorical variables. Odds Ratio, with 95\% confidence interval, was calculated to estimate the strength of association between potential risk factors and smoking status (outcome variable). Z-test was used for comparison of 2 sample proportions [10,11].

\section{RESULTS}

The age of the participants (in all sub-groups) ranged from 11 to 78 years. Mean age $( \pm \mathrm{SD})$ of participating employees was $34.5 \pm 10.3$ years, as compared to $16.2 \pm$ 0.98 (high school students); $19.97 \pm 1.7$ and $30.9 \pm 12.7$ in university students and clubs and malls attendees, respectively.

\subsection{Prevalence of Smoking}

The prevalence of current smoking among employees was $17.6 \%$ (33.6\% among males, but only $1.6 \%$ among 
females), $(p \leq 0.05)$. In addition, the prevalence of current smoking among males was $25.2 \%$ versus $9 \%$ among females among high school students' sample; $29.2 \%$ among university students' males as compared to $5 \%$ among university students' females ( $\mathrm{p} \leq 0.05) ; 34.6 \%$ among malls/clubs' males compared to only $8.2 \%$ among females in the same population subgroups $(\mathrm{p} \leq 0.05)$

Table 1.

Table 2 reflects on type of smoking in our studied groups, where cigarettes represented the pattern of smoking in $48 \%-68 \%$; and water pipe was the type in $8 \%$ $49 \%$, with higher preponderance of water-pipe smoking among female smokers, in general.

\subsection{Knowledge about Harmful Effects of Smoking and Attitude towards Tobacco Use}

Mean knowledge score was found to be higher among males in the employees' sample and in the high school students' sample with statistically significant difference between both sexes, while there was no sex difference regarding the mean knowledge score in the university students' sample and clubs and malls attendees' sample. Nevertheless, the mean attitude score (against smoking) was found to be different, in favour of females, in the 4 population subgroups (Table 3).

\subsection{Being a Male Is Considered a Potential Predictor to Smoking}

Table 4 shows that male gender was found to be a predictor of smoking in all studied groups, with an OR ranging from 3.4 (high school students) to 36 (employees). 95\% confidence intervals around these odds ratios supported this observed finding.

\subsection{Pattern of Smoking among the Four Population Subgroups}

A good proportion of female and male $(31 \%-75 \%)$ smokers in the 4 studied sub-groups reported that most or all of their friends smoke, but the difference was not always statistically significant (Table 5).

About half of smoking males in the high school students' sample reported that they prefer to smoke anywhere (49.2\%) while almost half of smoking females (46.7\%) reported "cafeterias" as favorite places for smoking. The difference between both sexes was found to be statistically significant for favorite place for smoking: social clubs $(Z=2.88$ and $p=0.004)$ and anywhere $(Z=$ 2.83 and $\mathrm{p}=0.005$ ) (Table 6).

Table 1. Prevalence of tobacco consumption among the four population subgroups by gender.

\begin{tabular}{|c|c|c|c|c|c|c|c|c|}
\hline \multirow{2}{*}{ Population subgroup } & \multicolumn{2}{|c|}{ Smokers } & \multicolumn{2}{|c|}{ Non smokers } & \multicolumn{2}{|c|}{ Total } & \multirow{2}{*}{$\chi^{2}$} & \multirow{2}{*}{$\mathbf{p}$} \\
\hline & No. & $\%$ & No. & $\%$ & No. & $\%$ & & \\
\hline \multicolumn{9}{|l|}{ Employees' sample } \\
\hline Male & 168 & 33.6 & 332 & 66.4 & 500 & 100.0 & \multirow{3}{*}{176.5} & \multirow{3}{*}{$0.000^{*}$} \\
\hline Female & 8 & 1.6 & 492 & 98.4 & 500 & 100.0 & & \\
\hline Total & 176 & 17.6 & 824 & 82.4 & 1000 & 100.0 & & \\
\hline \multicolumn{9}{|c|}{ High school students' sample } \\
\hline Male & 126 & 25.2 & 374 & 74.8 & 500 & 100.0 & \multirow{2}{*}{64.28} & \multirow{2}{*}{$0.000^{*}$} \\
\hline Female & 45 & 9.0 & 455 & 91.0 & 500 & 100.0 & & \\
\hline \multicolumn{9}{|l|}{ University students' sample } \\
\hline Male & 146 & 29.2 & 354 & 70.8 & 500 & 100.0 & \multirow{3}{*}{103.3} & \multirow{3}{*}{$0.000^{*}$} \\
\hline Female & 25 & 5.0 & 475 & 95.0 & 500 & 100.0 & & \\
\hline Total & 171 & 17.1 & 829 & 82.9 & 1000 & 100.0 & & \\
\hline \multicolumn{9}{|c|}{ Clubs and malls attendees' sample } \\
\hline Male & 218 & 43.6 & 282 & 56.4 & 500 & 100.0 & \multirow{3}{*}{163.2} & \multirow{3}{*}{$0.000^{*}$} \\
\hline Female & 41 & 8.2 & 459 & 91.8 & 500 & 100.0 & & \\
\hline Total & 259 & 25.9 & 741 & 74.1 & 1000 & 100.0 & & \\
\hline
\end{tabular}

${ }^{*} \chi^{2}$ test and its p-value were found to be significant at $\leq 0.05$ levels. 
Concerning favorite places of smoking in the university students' sample, more than one third (35.6\%) of male smokers and $44 \%$ of female smokers reported cafe- terias as the preferable place for smoking. The difference between both sexes regarding preferable places for smoking was found to be not statistically significant $(\mathrm{p}>$

Table 2. Distribution of smokers in the four studied samples, according to type of smoking by gender.

\begin{tabular}{|c|c|c|c|c|c|c|c|c|c|c|}
\hline \multirow{2}{*}{$\begin{array}{l}\text { Population subgroup } \\
\text { (current tobacco users) }\end{array}$} & \multicolumn{2}{|c|}{ Cigarette } & \multicolumn{2}{|c|}{ Water-pipe } & \multicolumn{2}{|c|}{ Both } & \multicolumn{2}{|l|}{ Total } & \multirow{2}{*}{$\chi^{2}$} & \multirow{2}{*}{$\mathbf{p}$} \\
\hline & No. & $\%$ & No. & $\%$ & No. & $\%$ & No. & $\%$ & & \\
\hline Male & 116 & 69.1 & 17 & 10.1 & 35 & 20.8 & 168 & 100.0 & \multirow{3}{*}{4.14} & \multirow{3}{*}{0.126} \\
\hline Female & 4 & 50.0 & - & - & 4 & 50.0 & 8 & 100.0 & & \\
\hline Total & 120 & 68.1 & 17 & 9.7 & 39 & 22.2 & 176 & 100.0 & & \\
\hline \multicolumn{11}{|l|}{ High school students group } \\
\hline Male & 84 & 66.7 & 7 & 5.5 & 35 & 27.8 & 126 & 100.0 & \multirow{2}{*}{4.85} & \multirow{2}{*}{0.08} \\
\hline Female & 29 & 64.4 & 7 & 15.6 & 9 & 20.0 & 45 & 100.0 & & \\
\hline \multicolumn{11}{|l|}{ University students group } \\
\hline Male & 70 & 47.9 & 11 & 7.6 & 65 & 44.5 & 146 & 100.0 & \multirow{3}{*}{0.87} & \multirow{3}{*}{0.649} \\
\hline Female & 10 & 40.0 & 3 & 12.0 & 12 & 48.0 & 25 & 100.0 & & \\
\hline Total & 80 & 46.8 & 14 & 8.2 & 77 & 45.0 & 171 & 100.0 & & \\
\hline \multicolumn{11}{|l|}{ Clubs and malls attendees } \\
\hline Male & 104 & 47.7 & 35 & 16.1 & 79 & 36.2 & 218 & 100.0 & \multirow{3}{*}{3.67} & \multirow{3}{*}{0.059} \\
\hline Female & 20 & 48.8 & 11 & 26.8 & 10 & 24.4 & 41 & 100.0 & & \\
\hline Total & 124 & 47.9 & 46 & 17.8 & 89 & 34.5 & 259 & 100.0 & & \\
\hline
\end{tabular}

${ }^{*} \chi^{2}$ test and its p-value were found to be significant at $\leq 0.05$ levels.

Table 3. Relationship between mean knowledge score, mean attitude score and gender among study samples.

\begin{tabular}{|c|c|c|c|c|}
\hline \multirow{2}{*}{$\begin{array}{c}\text { Knowledge } \\
\text { level }\end{array}$} & Employees (1000) & $\begin{array}{l}\text { High school students } \\
\text { (1000) }\end{array}$ & $\begin{array}{c}\text { University students } \\
\text { (1000) }\end{array}$ & $\begin{array}{l}\text { Clubs and malls attendees } \\
\qquad(\mathbf{1 0 0 0})\end{array}$ \\
\hline & Mean $\pm \mathrm{SD}^{* *}$ & Mean \pm SD & Mean \pm SD & Mean \pm SD \\
\hline \multicolumn{5}{|l|}{ Gender } \\
\hline Male & $21.0 \pm 5.7$ & $18.3 \pm 7.0$ & $18.5 \pm 5.2$ & $17.8 \pm 5.6$ \\
\hline Female & $20.3 \pm 4.9$ & $16.7 \pm 7.0$ & $18.0 \pm 4.4$ & $17.9 \pm 5.3$ \\
\hline F-test & $\mathrm{F}=5.21, \mathrm{p}=0.023^{*}$ & $\mathrm{~F}=11.91, \mathrm{p}=0.001^{*}$ & $\mathrm{~F}=1.71, \mathrm{p}=0.087$ & $\mathrm{~F}=0.14, \mathrm{p}=0.708$ \\
\hline \multirow[t]{2}{*}{ Attitude level } & Employees (1000) & High school students (1000) & $\begin{array}{l}\text { University students } \\
\text { (1000) }\end{array}$ & Clubs and malls attendees (1000) \\
\hline & Mean \pm SD & Mean \pm SD & Mean \pm SD & Mean \pm SD \\
\hline \multicolumn{5}{|l|}{ Gender } \\
\hline Male & $94.6 \pm 8.98$ & $91.2 \pm 10.1$ & $94.1 \pm 9.5$ & $91.6 \pm 8.97$ \\
\hline Female & $97.7 \pm 6.9$ & $92.8 \pm 9.6$ & $99.5 \pm 7.0$ & $96.6 \pm 7.4$ \\
\hline F-test & $\mathrm{F}=36.89, \mathrm{p}=0.000^{*}$ & $\mathrm{~F}=7.23, \mathrm{p}=0.007^{*}$ & $\mathrm{~F}=10.18, \mathrm{p}=0.000^{*}$ & $\mathrm{~F}=91.47, \mathrm{p}=0.000^{*}$ \\
\hline
\end{tabular}

${ }^{*}$ F-test and its p-value were found to be significant at $\leq 0.05$ levels; ${ }^{* *} \mathrm{SD}=$ Standard Deviation. 
Table 4. Association between smoking status and gender as potential predictor.

\begin{tabular}{|c|c|c|c|c|c|c|}
\hline \multirow{2}{*}{ Population subgroup } & \multicolumn{2}{|c|}{ Smokers } & \multicolumn{2}{|c|}{ Never smoker } & \multirow{2}{*}{ Total } & \multirow{2}{*}{ OR 95\% CI } \\
\hline & No. & $\%$ & No. & $\%$ & & \\
\hline \multicolumn{7}{|l|}{ Employees group } \\
\hline Male & 168 & 37.3 & 282 & 62.7 & 450 & \multirow{3}{*}{$36.3 ;(17.6-74.8)^{*}$} \\
\hline Female & 8 & 1.6 & 487 & 98.4 & 495 & \\
\hline Total & 176 & 18.6 & 769 & 81.4 & 945 & \\
\hline \multicolumn{7}{|l|}{ High school students group } \\
\hline Male & 126 & 25.3 & 373 & 74.7 & 499 & \multirow{3}{*}{$3.4 ;(2.3-4.9)^{*}$} \\
\hline Female & 45 & 9.0 & 454 & 91.0 & 499 & \\
\hline Total & 171 & 17.1 & 827 & 82.9 & 998 & \\
\hline \multicolumn{7}{|l|}{ University students group } \\
\hline Male & 146 & 31.5 & 318 & 63.5 & 464 & \multirow{3}{*}{$8.6 ;(5.5-13.5)^{*}$} \\
\hline Female & 25 & 5.1 & 470 & 94.9 & 495 & \\
\hline Total & 171 & 17.8 & 788 & 82.2 & 959 & \\
\hline \multicolumn{7}{|l|}{ Clubs and malls attendees } \\
\hline Male & 218 & 50.1 & 217 & 49.9 & 435 & \multirow{3}{*}{$10.5 ;(7.3-15.2)^{*}$} \\
\hline Female & 41 & 8.7 & 429 & 91.3 & 470 & \\
\hline Total & 259 & 28.6 & 646 & 71.4 & 905 & \\
\hline
\end{tabular}

*Significant risk factor.

\subsection{5) (Table 6).}

\section{DISCUSSION}

\subsection{Tobacco Use and Gender among High School Students}

It was found in the present study that the prevalence of current tobacco use among high school students' sample was $17.1 \%$. A lower prevalence $(12 \%)$ was reported in a cross sectional study of smoking among 1930 students in grades 7, 9 and 12 in Alexandria (2005) [12]. Smoking prevalence among male high school students (25\%) was significantly higher than among females (9\%). Similarly, there was an observed gender difference in the prevalence of current tobacco use in the 2001 Egypt Global Youth Tobacco Survey-GYTS [13] (22.8\% of males compared to $15.8 \%$ of females) and in the 2005 Egypt GYTS [14] (17.6\% of males versus $8.6 \%$ of females). In contrast to the previous studies, Gadalla et al. (2003) [15] reported that there were no female current smokers and there were $11.5 \%$ male current smokers only in their smoking study among rural high school students. The gender difference in tobacco use observed in our study may be attributed to cultural factors associated with patriarchal societies, such as that smoking may be viewed as an acceptable male social behavior, while being considered a cultural taboo for females. Accordingly, the relatively low smoking rates among females may simply be a reflection of a cultural taboo and may be underestimate or under reporting of the true female prevalence, since many young females may be reluctant to admit to smoking [16].

\subsection{Tobacco Use and Gender among University Students}

The present survey revealed that about $17.1 \%$ of university students' sample was current tobacco users. This result seemed intermediate between higher rates reported by Tawfik (2006) [17] among Alexandria university students (33.5\%) and Gadalla et al. (1992) [18] among Ain Shams University students $37.9 \%$; and the much lower rate (12.2\%) reported by Refaat (2004) [19] among Suez Canal university students. However the previous comparisons should be taken with caution due to differences in methodology including sample size and methods of data collection as well as sampling techniques.

University students' males were more likely to smoke than females in our survey $(29.2 \%$ versus $5 \%$, respectively). Similarly but a higher scale in other studies in 
Table 5. Distribution of current tobacco users of the four population subgroups by their gender and smoking friends.

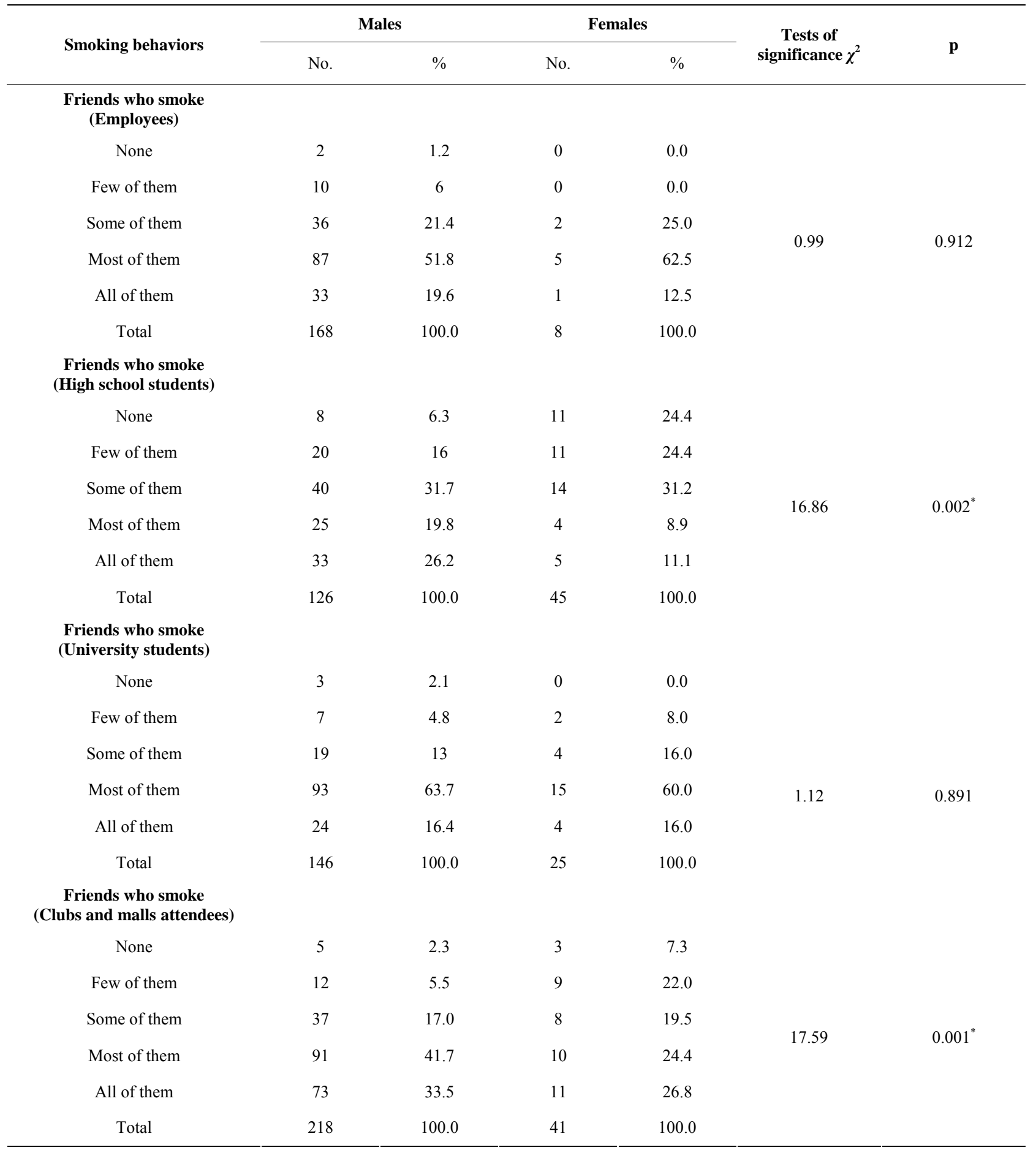

\footnotetext{
${ }^{*} \chi^{2}$ test and its p-value were found to be significant at $\leq 0.05$ levels.
}

Egypt, Tawfik (2006) [17] reported 55\% of males and $12 \%$ of females were smokers, and Gadalla et al. (1992) [18] reported $52 \%$ of males and $9 \%$ of females. Other studies in the Eastern Mediterranean Region (EMR) on smoking prevalence reported $15.1 \%$ among students in Sharjah University, UAE (33\% of males and $3.9 \%$ of females) [20]; 28.6\% among Jordan University of Science and Technology students $(50 \%$ among males and $6.5 \%$ among females) [21] and among King Saud University, Riyadh, Saudi Arabia, $32.7 \%$ of male undergraduates, compared to only $5.9 \%$ among females reported smoking in the year 2010 [22]. 
Table 6. Distribution of current tobacco users among high school and university samples by their gender and favorite places for smoking.

\begin{tabular}{|c|c|c|c|c|c|c|}
\hline \multirow{2}{*}{ Favorite place for smoking } & \multicolumn{2}{|c|}{ Males } & \multicolumn{2}{|c|}{ Females } & \multirow{2}{*}{$\begin{array}{c}\text { Tests of significance } \\
\text { Z }\end{array}$} & \multirow{2}{*}{$\mathbf{p}$} \\
\hline & No. & $\%$ & No. & $\%$ & & \\
\hline \multicolumn{7}{|l|}{ High school students sample* } \\
\hline Social clubs & 3 & 2.4 & 9 & 20 & 2.88 & $0.004^{* *}$ \\
\hline Cafeterias & 44 & 34.9 & 21 & 46.7 & 1.37 & 0.17 \\
\hline Home & 4 & 3.2 & 3 & 6.7 & 0.87 & 0.387 \\
\hline Bathrooms & 12 & 9.5 & 3 & 6.7 & 0.63 & 0.53 \\
\hline Anywhere & 62 & 49.2 & 12 & 26.7 & 2.83 & $0.005^{* *}$ \\
\hline Other places & 5 & 4.0 & 6 & 13.3 & 1.73 & 0.08 \\
\hline \multicolumn{7}{|l|}{ University students' sample ${ }^{* *}$} \\
\hline University & 28 & 19.2 & 3 & 12 & 0.99 & 0.323 \\
\hline Social clubs & 4 & 2.7 & 1 & 4 & 0.30 & 0.761 \\
\hline Cafeterias & 52 & 35.6 & 11 & 44 & 0.78 & 0.433 \\
\hline Home & 12 & 8.2 & 1 & 4 & 0.93 & 0.352 \\
\hline Bathrooms & 5 & 3.4 & 1 & 4 & 0.14 & 0.891 \\
\hline Anywhere & 46 & 31.5 & 9 & 36 & 0.43 & 0.664 \\
\hline
\end{tabular}

${ }^{*}$ Categories are not mutually exclusive; ${ }^{* *} \mathrm{Z}$ test and its p-value were found to be significant at $\leq 0.05$ levels.

In fact, there was a reported gender difference regarding smoking prevalence in most, if not all smoking studies that address university students. Females and males belonging to this age group have their own reasons for smoking; these reasons are part of the justification of their behavior as well as reflections of the prevailing socio cultural structure. One of the causes of the differences between genders could be the influence of the traditional culture that downgrade and disgrace females who smoke, however the previously mentioned traditional restriction of smoking among females is changing as many females nowadays believe that they could gain their personal and interpersonal worth through smoking specially in public places which they consider as a way of gaining value; this may suggest that there may be underreporting and underestimation of the total smoking prevalence and among females particularly [23].

\subsection{Tobacco Use and Gender among Social Clubs and Malls' Attendees}

This work revealed that $25.9 \%$ of participating attendees from social clubs and shopping malls were current tobacco users with much higher prevalence among males than females ( $43.6 \%$ of males versus $8.2 \%$ of females).
This may reflect that smoking among men is viewed as a strong sense of social acceptance, social bonding and was seen as a "normal" part of "being a man". On the other hand, smoking among women may be still perceived as misbehavior. However, it is observed that many young males and females in Egypt (particularly of higher social class; highly educated) visit cafés frequently in order to smoke; usually preferring to use water-pipe. There are few studies in Egypt that address tobacco use among attendees of cafés and malls; Youssef (2002) [24] reported 27.2\% prevalence of current tobacco use in a household survey in Alexandria among 2120 participants aged 15 to 86 years old through cluster sampling, with prevalence of $48.5 \%$ among males compared to very low prevalence among females $(1.5 \%)$. The higher prevalence of smoking among females in the present work compared to that of Youssef survey [24] is expected and could be due to the different setting in both studies as interviewing females in the malls and clubs may have been better (the place where women and girls are more likely to enjoy smoking without much of familial or parental opposition, to feel free to report smoking and to use any form of tobacco than before within the recent spread of a large number of coffee shops). 


\subsection{Higher Water Pipe Consumption among Females}

It is very obvious in this study that the proportion of water pipe smoking among smoking females is higher than among smoking males in the high school students' sample, university students' sample and clubs and malls attendees' sample. Water pipes are commonly used by women in the EMR of different ages and it has been suggested that water pipe smoking is generally more positively perceived than cigarette smoking for women [25]. Today, EMR/Arab girls and young women are increasingly using water pipes, as they perceive this type of smoking fashionable and means of social gatherings, where many restaurants and cafés across the region serve them almost all day long, coming in different flavors, to attract even more women and girls [26]. We consider this a growing catastrophe, as a woman smoker not only affects her own health, but also her spouse's (if he is not a smoker himself) and her children. In fact, she should be a role model for her growing off-springs and her peers at work, home and community.

\subsection{Knowledge about Harmful Effects of Smoking and Attitude towards Tobacco Use}

There was no sex difference regarding mean knowledge score in the university students' sample in the present study. Similarly Tawfik (2006) [17] revealed the same findings in a study of smoking among university students in Alexandria. As the present work found that mean attitude score was significantly higher among females, Tawfik [17] reported also higher mean attitude scores among females. Nevertheless, there was a statistically significant difference in the mean knowledge scores between both genders in our work in the high school students' and health related employees' samples. Other studies demonstrated that females have more knowledge and positive attitude compared to males towards tobacco related issues [27,28]. A similar finding was revealed in a smoking study of knowledge and attitude by gender among Malaysian adults aged 18 years and above; as females were found to have more negative attitude (unfavorable attitude) towards smoking in comparison to males [29].

The unfavorable attitude towards smoking revealed by women and girls in the previous tobacco studies might be due to observance of local customs in which smoking is not considered as an acceptable behavior among women; particularly in our Egyptian culture. This provides a golden opportunity for behavior change through the involvement of family members in anti smoking programs. Advice and encouragement by spouse, mother or sister on smoking cessation and hazards of smoking may in- fluence male family members to stop smoking or deter those who do not smoke from initiating [30].

\subsection{Gender and Tobacco Use among the Four Population Subgroups}

The present study revealed that being a male seems to increase the probability of being a smoker. Male gender was found to be a predictor of smoking in all studied groups, with an odds ratio ranging from 3.4 (high school students) to 36 (employees). "Gender" socially determined role for each sex provides the social explanation of sex linked patterns of tobacco use [31]. In most of the world, being born male is the greatest predictor of tobacco use with overall prevalence about 4 times higher among men than women globally (48\% versus $12 \%)$ [32].

During the mid-twentieth century, growing social acceptance of women's smoking contributed to increased smoking adoption by women. Sex role norms and general expectations concerning gender-appropriate behavior have had a variety of effects on gender differences in smoking. First, general characteristics of traditional sex roles, including men's greater social power and generally greater restrictions on women's behavior, contributed to widespread social pressures against women's smoking. Second, traditional sex role norms and expectations have fostered gender differences in personal characteristics and experiences which influence smoking adoption. Finally, certain aspects of sex roles have contributed to gender differences in appraisal of the costs and benefits of smoking. For example, physical attractiveness is emphasized more for females and the contemporary beauty ideal is very slender, so females are more likely to view weight control as a benefit of smoking [33].

\subsection{Pattern of Smoking among the Four Population Subgroups}

It was reported in the current study that "Cafeteria" (or café) was a favorable place for smoking among females as mentioned by $46.7 \%$ of smoking females, while $49.2 \%$ of smoking males prefer to smoke anywhere. This pattern was similar among high school students in Tayel's study [34], where students mentioned that most the favorable place to smoke was outside their homes. Tawfik (2006) [17] also reported "Cafeteria" as the favorable place for smoking among both sexes $(64.3 \%$ of males and $30.8 \%$ of females).

The majority of smoking males and females $(80 \%$ and $76 \%$ respectively) had most or all of their friends who smoke. Mandil et al. (2005) [20] in a study of tobacco consumption among university of Sharjah students found that most smokers $(86.7 \%)$ had one or more friends who smoked. This is a fact which was also confirmed by King 
Saud University students in another recent study carried out in 2010 [22].

\section{CONCLUSION \& RECOMMENDATIONS}

- Innovative female oriented health education sessions should be planned, implemented and evaluated in different Egyptian community settings, including social clubs, religious institutions, shopping malls and other settings as deemed appropriate. This awareness should emphasize that smoking endangers not only women's health, but also threatens the health of her spouse, her embryo and her children. Such programs should be coordinated between national tobacco control programs and civil services organizations.

- Textual health warnings should reflect gender specific patterns of tobacco use and consequences of smoking.

- Comprehensive gender based school tobacco policies should be established and implemented. These policies should include strong bans on tobacco use on school grounds and at school functions, tobacco prevention curricula, access to quitting services for students.

- Enforcing existing tobacco control legislative and administrative measures for protection from exposure to tobacco smoke in workplaces, educational institutions, public transport and other public places including restaurants and cafes as well as social and sporting clubs.

- Printing rotating messages and pictures on water-pipe instruments that carry health warnings describing the harmful effects of water-pipe use.

- Fostering public and non-governmental efforts for tobacco control.

- Assisting smokers to quit smoking through tobacco cessation programs.

- Encouraging further research which provides stronger evidence for sound and informed policy and decision making.

\section{REFERENCES}

[1] Shafey, O., Eriksen, M., Ross, H. and Mackay, J. (2009) The tobacco atlas. 3rd Edition, American Cancer Society, Atlanta.

[2] WHO (2009) Report on the global tobacco epidemic, 2009. Implementing smoke-free environments. WHO, Geneva.

[3] WHO (2008) Report on the global tobacco epidemic, 2008. The MPOWER package. WHO, Geneva.

[4] WHO (2006) Tobacco: Deadly in any form or disguise. WHO, Geneva.

[5] Guidon, G. and Boisclair, D. (2003) Past, current and future trends in tobacco use. HNP Discussion Paper, Economics of Tobacco Control Paper, No. 6, WHO, Geneva.
[6] Lwanga, S.K. and Lemeshow, S. (1991) Sample size determination in health studies. A practical manual. WHO, Geneva.

[7] WHO (1983) Guidelines for the conduct of tobacco smoking surveys of the general population. WHO, Geneva.

[8] Egyptian Smoking Prevention Research Institute (2002) Tools for tobacco consumption surveys in Egypt. Ministry of Health \& Population, Cairo.

[9] WHO (1996) Guidelines for controlling and monitoring the tobacco epidemic. WHO, Geneva.

[10] Jekel, J.F., Katz, D.L. and Elmore, J.G. (2001) Epidemiology, biostatistics and preventive medicine. 2nd Edition, WB Saunders Company, Philadelphia.

[11] Feinstein, A.R. (2002) Principles of medical statistics. 1st Edition, Chapman and Hall/CRC, Boca Raton.

[12] Islam, S.M. and Johnson, C.A (2005) Influence of known psychosocial smoking risk factors on Egyptian adolescents' cigarette smoking behavior. Health Promotion International, 20, 135-145. doi:10.1093/heapro/dah604

[13] Global Youth Tobacco Survey Egypt (2001) Global youth tobacco survey fact sheet. http://www.cdc.gov/tobacco/global/gyts/factsheets/emr/2 005/Egypt factsheets.htm

[14] Smoking and Tobacco Use (2005) Fact sheet: EMR global youth tobacco survey, Egypt. http://www.cdc.gov/tobacco/global/gyts/factsheets/emr/2 005/Egypt factsheets.htm

[15] Gadalla, S., Aboul-Fotouh, A., El-Setouhy, M., Mikhail, N., Abdel Aziz, F. and Mohamed M.K. (2003) Prevalence of smoking among rural secondary students in Qualyobia. Journal of the Egyptian Society of Parasitology, 33, 10311050.

[16] Islam, S.M. and Johnson, C.A. (2003) Correlates of smoking behavior among muslims Arab-American adolescents. Ethnicity and Health, 8, 319-337. doi:10.1080/13557850310001631722

[17] Tawfik, H.A. (2006) Assessment of smoking behavior among university students using the social learning theory. University of Alexandria, High Institute of Public Health, Alexandria.

[18] Gadalla, M.A., Gabal, M.S. and Khella, A.K. (1992) When and why Ain Shams university students started smoking? Journal of the Egyptian Public Health Association, 67, 267-290.

[19] Refaat, A. (2004) Practice and awareness of health risk behaviors among Egyptian university students. Eastern Mediterranean Health Journal, 10, 72-81.

[20] Mandil, A., Hussein, A., Omar, H., Turki, G. and Gaber, I (2007) Characteristics and risk factors of tobacco consumption among university of Sharjah students. Eastern Mediterranean Health Journal, 13, 1449-1458.

[21] Haddad, L.G. and Malak, M.Z (2002) Smoking habits and attitudes towards smoking among university students in Jordan. International Journal of Nursing Studies, 39, 793802. doi:10.1016/S0020-7489(02)00016-0

[22] Mandil, A., BinSaeed, A., Ahmad, S., Al-Dabbagh, R., Alsaadi, M. and Khan, M. (2010) Smoking among uni- 
versity students: A gender analysis. Journal of Infection and Public Health, 3, 179-187. doi:10.1016/j.jiph.2010.10.003

[23] Edrogan, N. and Edrogan, I. (2009) Smoking at school: Views of Turkish university students. International Journal of Environmental Research and Public Health, 6, 3650.

[24] Youssef, R.M., Abou-Khatwa, S.A. and Fouad, H.M (2002) Prevalence of smoking and age of initiation in Alexandria, Egypt. Eastern Mediterranean Health Journal, 8, 626637.

[25] Maziak, W., Rastam, S., Eissenberg, T., Asfar, T., Hammal, F., Bachir, M., et al. (2004) Gender and smoking status based analysis of views regarding waterpipe and cigarette smoking in Aleppo, Syria. Preventive Medicine, 38, 479-484.

[26] Maziak, W., Ward, K.D., Afifi-Soweid, R.A. and Eissenberg, T. (2004) Tobacco smoking using a waterpipe: A reemerging strain in a global epidemic. Tobacco Control, 13, 327-333. doi:10.1136/tc.2004.008169

[27] Omair, A., Kazmi, T. and Alam, S.E. (2004) Smoking prevalence and awareness about tobacco related diseases among medical students of Ziauddin Medical University. Journal of the Pakistan Medical Association, 52, 389-392.

[28] Al-Haqwi, A.I., Tamim, H. and Asery, A. (2010) Knowl- edge, attitude and practice of tobacco smoking by medical students in Riyadh, Saudi Arabia. Annals of Thoracic Medicine, 5, 145-148.

[29] Lim, K.H., Sumami, M.G., Amal, N.M., Hanjeet, K., Wan Rozita, W.M., and Nrhamimah, A. (2009) Tobacco use, knowledge and attitude among Malaysians age 18 and above. Tropical Biomedicine, 26, 92-99.

[30] Ma, G.X., Fang, C.Y., Tan, Y. and Feeley, R.M (2003) Perceptions of risks of smoking among Asian Americans. Preventive Medicine, 37, 349-355. doi:10.1016/S0091-7435(03)00143-9

[31] Cortenay, W.H. (2000) Constructions of masculinity and their influence on men's well being: A theory of gender and health. Social Science \& Medicine, 50, 1385-1401. doi:10.1016/S0277-9536(99)00390-1

[32] Carrao, M.A., Guindon, G.E., Cokkinides, V. and Sharma, N. (2000) Building the evidence base for global tobacco control. Bulletin of the World Health Organization, 78, 884-890.

[33] Waldron, I. (1991) Pattern and causes of gender differences in smoking. Social Science \& Medicine, 32, 9891005. doi:10.1016/0277-9536(91)90157-8

[34] Tayel, K.Y. (1990) The problem of smoking among secondary students in Alexandria. University of Alexandria, High Institute of Public Health, Alexandria. 